\title{
The Role of Multi-Purpose Cooperatives in the Economic Development in Ethiopia, The Case of Lalo-Assabi District (West Wollega Zone, Oromia Regional State)
}

\author{
Desalegn Fekadu Etefa \\ Ambo University: Institute of Cooperatives and Development Studies, Department of Cooperative
}

\begin{abstract}
The objective of this study is to show the overall development trends and the challenges encountering the multipurpose cooperatives (MPCs). To do so, research methodology employed was descriptive, which involved both qualitative and quantitative methods. Data were collected from both primary and secondary sources. The primary data were collected from the sample through cross-sectional survey from 210 respondents. Besides, 16 key informants and three focus group discussions (FGDs) were considered in the assessment. The instruments used were questionnaires, FGDs, in depth interviews, observation and document review. Both probability and nonprobability sampling techniques were applied. Data analyses were done using descriptive statistics. The result of the study shows the average rate of growth of members in sample MPCs is $19 \%$ as calculated from 20162018 and $79.3 \%$ from their formation period. The capital of the MPCs increased from 305,081 to 9.3 million and their profit was nearly 1.5 million ETB. Of the multifaceted services they provide, marketing agricultural inputs accounts for the great proportions. In general, the sample MPCs are contributing somewhat in the economic development. However, their performance is not as expected due to major problems identified: lack of professional managers, devoted management committees, limited capital base; weak horizontal and vertical linkages, low members' participation, insufficient dividend, lack of diversified activities; limited awareness, inadequate infrastructure, low stakeholders' participation, lack of adequate credit and necessary technical supports are among the hitches to be tackled. Hence, to unleash and sustain their development potential, proposed interventions to be taken are: Building the capacity of the management committees and their staff, hiring professional staffs, providing credit services, promoting members participation, establishing strong linkage, providing infrastructural facilities, providing technical support and etc. to mitigate the problems.
\end{abstract}

Keywords: Cooperatives, Economic Contribution, Local Development, Multi-purpose Cooperatives.

DOI: $10.7176 /$ RHSS/9-21-03

Publication date: November $30^{\text {th }} 2019$

\section{Introduction}

In the contemporary period, poverty is abolishing the lives of billions of the people around the world. As a result, many people sense incapable to change their lives. In this hardship situation where alleviation of poverty has become the biggest challenge to the human society, cooperatives emanated to be among the alternatives economic opportunity. Cooperatives are formed to meet peoples' common requirements. They are originated on the leading idea that together, a group of people can achieve goals that none of them could attain alone (Ruhul \& Mohammed, 2014).

As far as the unique character of cooperative is concerned, it is for the members, of the members and by the members. Thus, the members pool resources together; reduce costs, build capacities and thereby backup each other at the moment of great challenges (Bolton, 2019). Now days, poverty reduction is not only the concern of the government, but also a big issue to all the concerned including nongovernmental organizations and the society itself. There is consensus among many actors of development, comprising the United Nations (UN), United Nations Development Programme (UNDP), the International Cooperative Alliance (ICA) and the International Labour Organization (ILO), that cooperative enterprise is one of the new forms of organization that target for the reduction of poverty and exclusion (Alemu, 2011).

Evidence from various sources reveals that cooperatives are contributing great share to the country's economic and social development. For instance, report of the ICA (2016) stated that about one billion people are involved in cooperatives, either as members or, as employees or both. The same source further indicated that nearly 280 million people get employment opportunities from cooperatives at global level. The livelihoods of almost half of the world's population are secured by cooperative enterprises. This is particularly true in the rural areas where it offers an important potential for income earning and equity for the dwellers.

As historical proof indicated, in Ethiopia, cooperation as a way of life has been and remains to be a habit to find solutions to the socio-economic problems of the people. Modern forms of cooperatives were first hosted in Ethiopia in 1960 during the imperial Hailesillasie regime. Succeeding this, the Derge regime established an extensive network of socialist agricultural cooperatives all over Ethiopia by unifying the peasants. There was almost no member participation. Instead, party agents and political activists mostly ran these cooperative 
systems (Dessalegn, 1994). During this time, corruptions and mismanagements were so prevalent in the cooperatives, which handled the purchase of consumer goods for rural communities.

As indicated in the work of Kifle (2015), the present government of Ethiopia provided a legal framework which combined universally accepted principles of cooperatives including voluntary membership (Proclamation No. 147/1998 and 402/2004). Due to increased government support, cooperative movement has shown growth in Ethiopia (Islam et al., 2015). Moreover, the government abolished command economy, and declared liberalization of economy. Thus, cooperatives are promoted as part of Ethiopian rural and agricultural development strategies, within the national macro-economic policy framework of agricultural development led industrialization (ADLI). Following this, some improvements have been seen in cooperative societies in the country.

Many scholars have argued that cooperatives could play crucial roles in the socio-economic developments of the country if they are formed voluntarily and managed democratically. As to Adugna (2013), cooperatives are considered as an appropriate tool for rural development. In spite of such potential roles, many problems are identified as an obstacle to cooperatives' intended goals achievement. For instance, in the study of Nuradin (2015), problems deterring the role of cooperatives in the economic development were: backward attitude, lack of committed leadership, lack of good governance, lack of working capital, attitude and practice of corruption, lack of knowledge and skill, lack of provision and utilization of improved technology, weak vertical and horizontal linkage within and among cooperatives and inappropriate support from government and other stakeholders.

Of the numerous types of cooperatives, in this paper, the area of study is on multi-purpose cooperatives (MPCs) those who undertake diversified activities unlike the single purpose one. In line to the above fact, in the study area, the contribution of MPCs in the economic development, challenges they are facing and intervening strategies to be adopted have not been researched. Hence, the rationale of the study aims at assessing the issue and to fill the gaps by finding out the root causes of the problems as well as to investigate means of solutions for the existing problems.

\subsection{Description of the Study Area}

The study was conducted in the western part of Oromia Regional State mainly in Lalo-Assabi district, which is one of the 20 districts found in West Wollega Zone. It is located in the western part of a zone at a distance of 23 $\mathrm{km}$ away from the zonal capital (Gimbi town). It shares common boundaries with Gimbi, Guliso, Bodji and Yubdo districts and Benishangul-Gumuz Regional State. So, in terms of relative location, it is bounded by Gimbi town in the east, Guliso district in the west, Boji Cokorsa and Boji Dirmaji districts in the north, Ganji district in the south, Homa district in the south-east and Benishangul-Gumuz Regional State in the north-east. Enango town is the capital of the district. Astronomically the district extends roughly from $9^{0} 08^{\prime} 33^{\prime}$ 'N and $35^{\circ} 83^{\prime} 33^{\prime \prime} \mathrm{E}$.

The district has 31 administrative sub-divisions out of which 27 are peasant associations and the remaining 4 are urban centers. It has a total area of 43,355 hectares $\left(433.55 \mathrm{Km}^{2}\right)$ and total population of 96,068 of which 45,068 are males and 51,000 are females as of 2018. In terms of topography, it is characterized by ups and down train. The district generally lies with in an altitudinal range of 1500 to 1900 meters above sea level.

The district totally lies within "Woina Dega" agro climatic condition. Its average annual temperature is about $24.5^{\circ} \mathrm{C}$ while average annual rainfall is $1,737.5 \mathrm{~mm}$. As far as the natural vegetation of the district is concerned, about 1,893.07 hectares of the total area is covered by natural vegetation out of which wood land covers about 577.2 hectares while reverie covers about 12.8; shrubs and bushes cover about 456.1 hectares. Moreover, 847 hectares of manmade forest is protected by the community.

Agriculture is the main economic activities of the district. As data from west Wollega zone finance and economic development office shows, the district had 17 different types of cooperatives having 10,722 members. Of these, there are eight MPCs consisting 4,375 members. The major services delivered by the cooperatives for their members include provision of supply of agricultural inputs and market for their members by purchasing their products. With regard to the distribution of agricultural inputs, 10,330.675 quintals of fertilizers, 642.875 quintals of improved seeds, 550 litters of herbicides and $85 \mathrm{~kg}$ of pesticides were distributed to farmers.

\section{Definition and Conceptual Frameworks of Cooperatives}

As to the ICA, cooperatives are autonomous association of persons united voluntarily to meet their joint economic, social, and cultural needs and aspirations. They are people centered enterprises jointly owned and controlled by and for their members to realize their mutual socio-economic needs and aspirations. As enterprises; they are based on values and principles, they put fairness and equality first ensuing people to create sustainable enterprises that generate long-term jobs and prosperity (Zeuli \& CROOP, 2004). This shows cooperatives are voluntary associations geared towards the realization of the members' needs.

Others defined it as a registered voluntary association of persons with membership not less than ten persons, with a common interest formed and operated along democratic principles, for the purpose of economic and social 
interests at least costs, to its members who contribute the capital and manage the business so recognized by delegating some powers to elected management (Ruhul \& Mohammed, 2014).

Conceptually, cooperative is a non-profit based service organization owned and operated by its members. In several ways, it seems every other business, but it has unique characteristics. It has been the very basis of human civilization. The inter-dependent and the mutual help among human beings have been the groundwork of social life. It is the experience of universal social history that man cannot live by himself and for himself alone. Since the appearance of human society, individuals have found benefit in working together and helping one another in all over the world (Krishna, 1992 cited in Jemal, 2008).

A cooperative operates for the benefit of its members. These member-owners share equally in the control of their cooperatives. The members elect directors which, in turn, hire management to manage the daily dealings of the cooperative in a way that serves the members' safeties. It is built on the idea people working together for a mutual goal and mutual good (Ahmad, 2005).

Cooperatives can be classified from several angles including: groups served, size, areas served, functions performed, types of membership, legal status and financial structure. In terms of groups served, cooperatives may be classified as producer cooperatives and consumer cooperatives. While agricultural cooperatives are best examples of producer cooperatives; credit cooperatives, consumer good cooperatives and health care cooperatives are of consumer cooperatives (Williamson, 2000).

Cooperatives can also be classified as local and regional cooperatives based on the areas served. While generally local cooperatives operate from a trading center and have individuals as their members, regional cooperatives have their territories ranging from several countries to several states. As far as the functions of cooperatives are concerned, agricultural cooperatives perform one or a combination of the various functions for farmer-members including marketing purchasing services and bargaining (ibid).

With regard to the type of cooperatives operating in Ethiopia, Bezabih (2009) put further category based on the types of activities in which they engage. Consequently, cooperatives could engage in a single activity, such as production and marketing; or could be involved in multiple activities concurrently. In general, the types of cooperatives that operate in Ethiopia are Producers' cooperatives, marketing cooperatives, saving and credit cooperatives (SACCOs), consumer cooperatives, handcrafts cooperatives, mining cooperatives, housing cooperatives, construction cooperatives, MPCs and services cooperatives. Additional clarification given by Chukwu (1990) indicated that those who undertake diversified activities unlike single purpose cooperatives are MPCs. They are engaged in integrated structure of activities, planned according to member's requirements identified at the grass root level, taking the socio-economic life of the farmer members in its totality.

Cooperatives operate under seven principles which are articulated by the ICA in 1995 (Baarda, 2006). These are: Voluntary and Open Membership, Democratic Member Control, Member Economic Participation, Autonomy and Independence, Provision of Education, Training and Information,Cooperation among Cooperatives and Concern for the Community.

\subsection{Conceptual Frameworks of Factors Affecting Multi-Purpose Cooperatives}

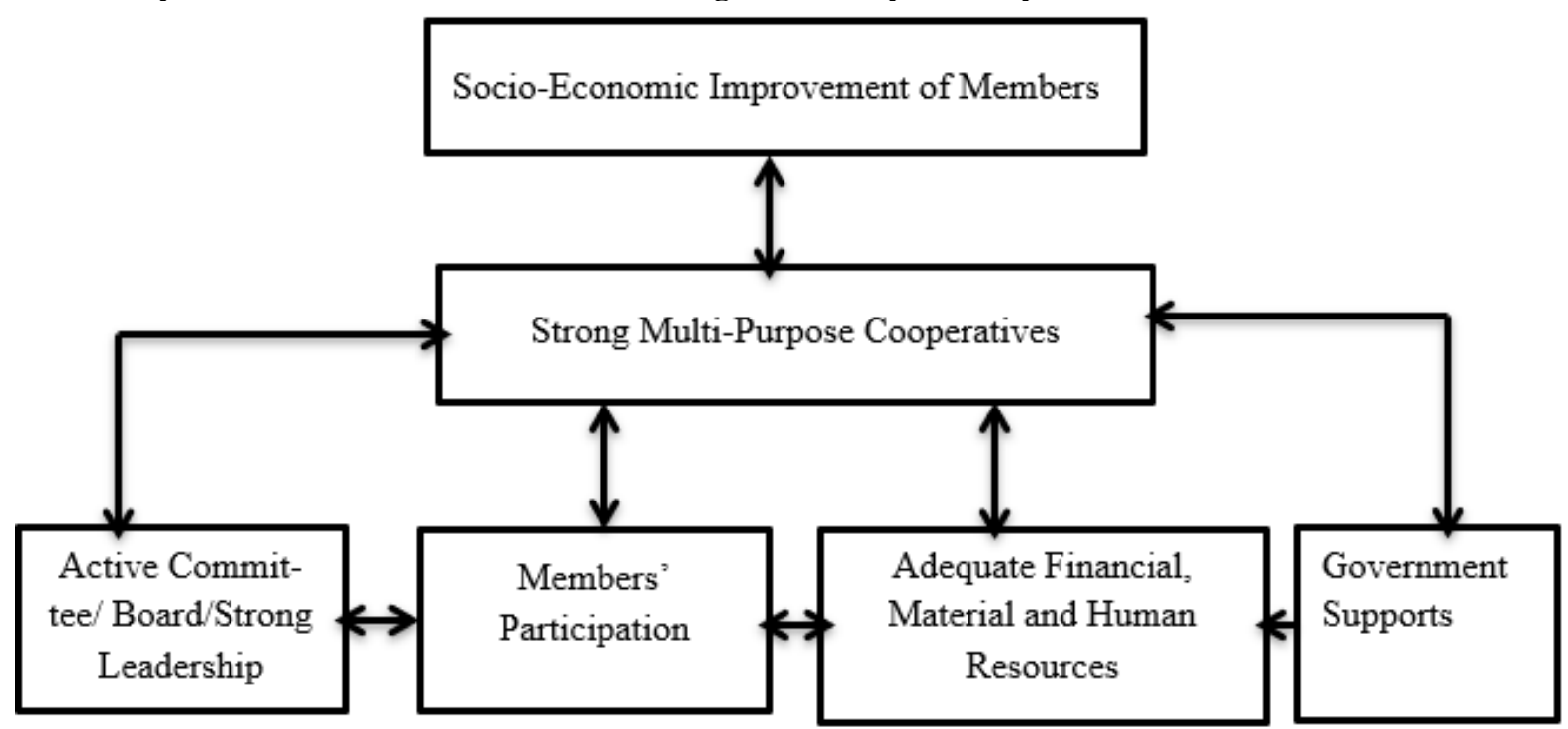

Source: Own construct, 2019

As indicated in the schematic diagram above, the presence of all those placed at the base of the tree can lead to the success of the multi-purpose cooperatives. According to Banaszak (2008), the key factors that contributed 
to cooperatives success, such as leadership strength, number and members' participation, sufficient resources and above all, government supports are among the major ones listed.

The internal factors that would have an effect on a cooperative's success are the ones that arise internally and these include members' commitment, members' participation, structural, communication and managerial factors.

The external factors, considered essential in the success of cooperative, include assistance that act as motivation for members in a cooperative, external assistance, government policies, regulatory frameworks and market factors. Those key factors indicated at the bottom of the diagram are independent variables while the one placed at the top is dependent variable. There are multi-interactions among these variables. That means, in case the interaction goes in the way contributing to its progress, the consequence would be positive, and the reverse might occur otherwise. In short, these factors can affect the competitiveness of cooperatives, especially in developing countries, where cooperatives are still underdeveloped. From these, it can be deduced that the vise-versa would take place in the absence of the above mentioned components.

\section{The Study Approach}

Mixed research design is used, which involves both the qualitative and quantitative approaches in a single study. As Creswell explained, all methods have limitations and felt that biases inherent in a single method could neutralize or cancel the prejudices of other methods (Creswell, 2006). From different strategic models of mixed approach the researcher selected descriptive design; collecting and analyzing quantitative data followed by collecting and analyzing qualitative data.

\subsection{Sources of Data}

With regard to the sources, both primary and secondary data sources were generated and used as an input for the research findings. The primary data sources were gathered using various data collection instruments such as household survey through questionnaire, focus group discussion, key informant interview and observation. The already produced materials like books, conference proceedings, official documents, statistical reports, web sites, and other relevant related literatures were used as a secondary data sources.

\subsection{Population, Sample and Sampling Techniques}

Since it was difficult to collect data from the population, sample of the selected respondents were the source of information. The intention of the study was to assess the role of multi-purpose cooperatives (MPCs) in the economic development of Lalo-Assabi district. There were eight MPCs which had 4,375 members. Of these, five MPCs were purposively selected and included in the sample respondents. The reason behind the selection for these five MPCs was constraint of time and finance.

In order to decide which MPCs have to be the sample frame, code is given to eight of them. Hereafter, the five sample frames were selected randomly by lottery method. These are Lalisa Lalo, Lalisa Buko, Burka Dongoro, Feyisa Keleyi and Bikiltu Atosi. These MPCs have 3,200 members. The sample constituted 62.5\% and $73 \%$ in terms of number of MPCs and number of members respectively.

To determine the sample size, at the first step, 89 members from each five MPCs were randomly selected that account to 445 in total. Following this, to get the exact respondents, the formula given by Yemane (1967) is used. The formula is: $\mathbf{n}=\mathbf{N} / \mathbf{1}+\mathbf{N}(\mathbf{e})^{\mathbf{2}}$, where $\mathbf{n}$ represents sample size, $\mathbf{N}$ represents population, and $\mathbf{e}$ is the desired level of precision (0.05) i.e., the likelihood that the answer will fall outside that range (the probability not to represent). Thus, depending on this formula, the sample size was 210 . Consequently, the valuable information for the study was gathered from 210 individuals through Crosse-sectional survey in connection to the objective of the thesis.

To assure the representation of the sample, each category is proportionately taken from all the five sampling frames i.e., from the 89 members by stratified sampling method. Hence, 42 individuals were proportionally involved in the sample respondents. The technique applied to obtain data from the identified sample size was simple random sampling.

In order to get further information, sixteen key informants were encompassed. These are: ten leaders that are two respondents from each of samples MPCS, two experts from Lalo-Assabi cooperative office, two experts from west Wollega zone cooperative office and two from Oromia region cooperative agency.

\subsection{Data Collection Tools}

To gather primary data during the study, the structured questionnaires were prepared in English and translated into Afan Oromo (local language) for the local people to understand the questionnaires and then translated back into English for analysis. The questionnaires were both close and open ended to get information in accordance to the research objectives. To carry on the collection of data, the researcher employed five enumerators that were selected, trained and sent to the sample respondents after preliminary test of the questions under the supervision 
of the researcher to check the validity of the instrument. The identified samples provided data through crosssectional survey.

Since it provides richer information while collecting data, interviews viz. through face to face conversation were also used. Accordingly, structured and semi-structured interview questions were prepared to collect data from the leaders of MPCs, experts of cooperative agency and office.

Furthermore, to get insight into perceptions and attitudes of participants about the issue, Focus Group Discussions (FGDs) were the other instrument. Existing conditions were also assessed and included in the analysis through observation method.

\subsection{Data Analysis and Presentation}

The data collected were carefully tallied. To make the data workable for the analysis, data were processed by editing, coding, classification and tabulation. In general, data were analyzed by descriptive statistics. These data were presented by using tabular and graphic form where necessary. Ultimately, both the qualitative and quantitative data were appropriately interpreted in the way they give meaningful sense for the readers. The qualitative data were interpreted by words particularly using coding, narrative and content analysis techniques. The quantitative data on the other hand were interpreted numerically by frequencies, percentages and averages.

\section{Results, Interpretation and Discussion}

\subsection{Socio-Economic Profile of Sample Respondents}

Under this sub-topic, personal information of the sample households like: the gender, age, family size, level of education, land ownership and livelihood activities and time of joining the MPCs have been presented, which in turn can serve as a background for the issues to be analyzed.

The gender profile of the study population indicates that $154(73.3 \%)$ of the respondents were males and 56 $(26.7 \%)$ of them were females. The reason for more number of male respondents is because of the fact that the majority of the households in rural community of Ethiopia are led by males.

With regard to their marital status, about $69 \%$ of the respondents were married $28 \%$ of them were single $1.4 \%$ of the households were divorced and the rest 1.4\% were widowed (Fig. 4.1). Of these, 37 (17.6\%) of them were not heads of the house. That means, $173(82.4 \%)$ of the respondents were households while the rest of them were not.

Figure 4.1: Marital Status of the Respondents

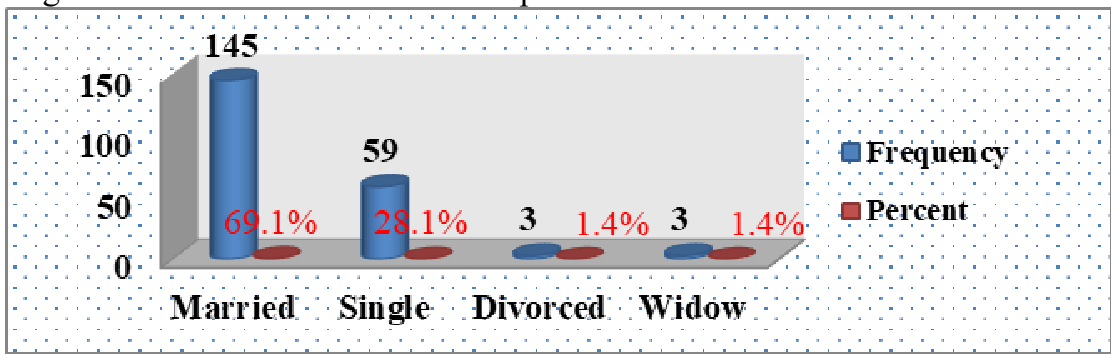

Source: Field Survey, 2019

The age category of the sample respondents is illustrated in Figure 4.2. Accordingly, the majority of the sample respondents (28.1\%) fall in the age category from 23-30 followed by 18-22 age category, which is about $20 \%$ of the sample respondents, whereas, the minority $(3.3 \%)$ fall in the age category above 65 . This shows more than $95 \%$ of the sample respondents are active age population. Thus, if they work hard, they can perform better assuming that other things are also enabling conditions.

Figure 4.2: Age of the Sample Respondents

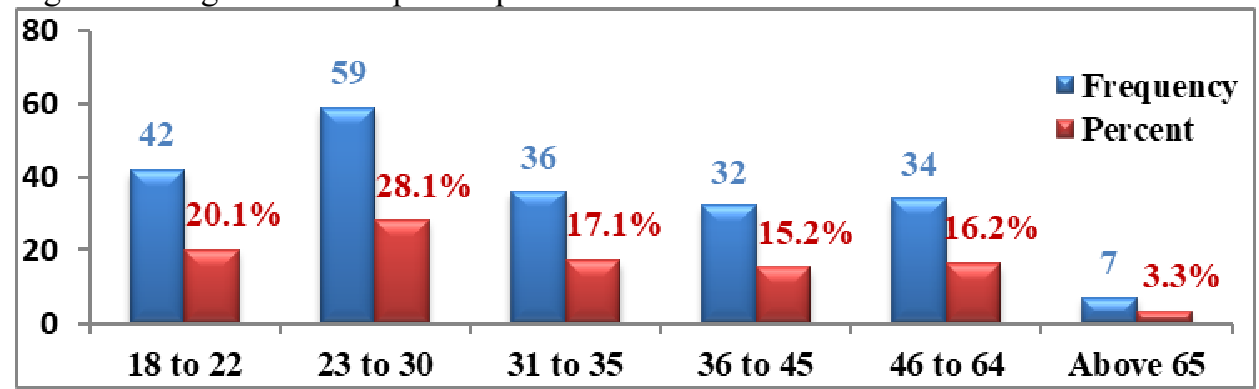

Source: Field Survey, 2019

Education is a basis for developing capacity to cope with the readily evolving and changing society in an information age. The knowledge on the wise use of scarce resources can be achieved only through education and training. They are only educated people that can command the skills necessary for sustainable growth and 
for the better quality of life (Desalegn, 2013).

As illustrated in Fig 4.3, significant number of sample respondents (41\%) were illiterate and only limited numbers $(7 \%)$ owned skills necessary to produce.

Figure 4.3: Educational Level of Respondents

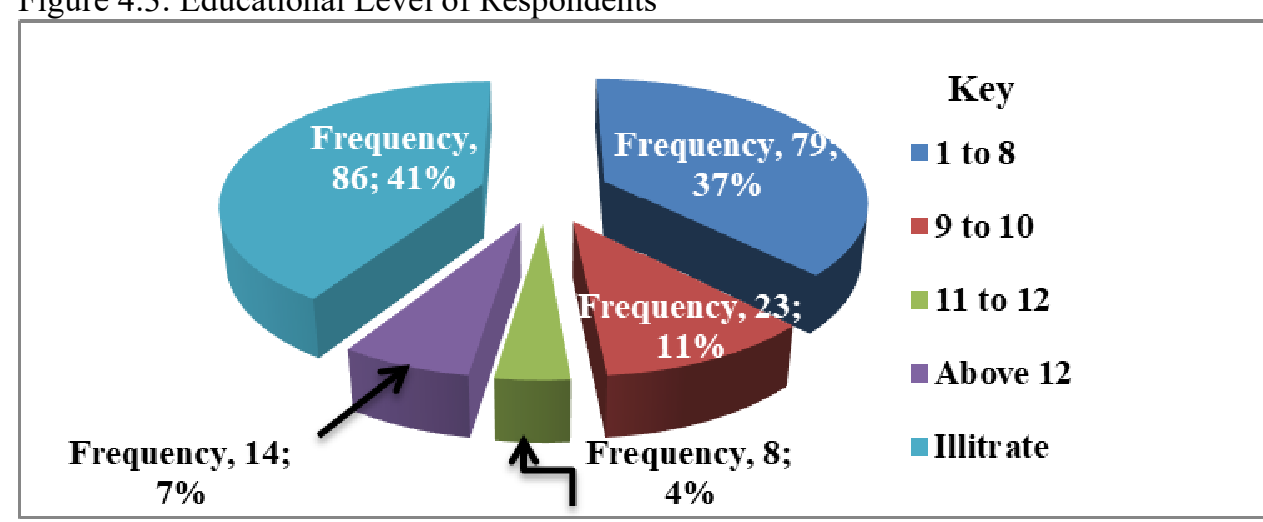

Source: Field Survey, 2019

The other characteristic considered in this study is the occupational status of respondents. In connection to this, about $85 \%$ of the respondents were engaged in farming and less than $15 \%$ of them are engaged in other occupation where $7.6 \%$ of them are daily laborers, $7.1 \%$ are employee of the selected MPCs; $2.4 \%$ NGO employee, $1.9 \%$ government employee and $2.9 \%$ were involved in other livelihoods like religious leaders (2), informal business (2) and students (2). From this, one can infer that farming is the principal economic activity for more than $85 \%$ of the sample respondents.

Land is one of the core driving production factors used by farmers for their crop production and rearing their livestock. Further, land in the rural part of the country are one of the major asset used as means of accessing to technological farm inputs and obtain extension services. As the current econometric evidence shows, land is one of the major conventional inputs that limit agricultural production Food and Agricultural Organization (FAO, 2005). Thus, this indicates access to land determines the performance of rural residents.

Regarding the possession of land in the study area, majority of the samples, which was nearly about $50 \%$ of sample respondent own land area ranging from 0.5 to 1 hectare. This is not enough to produce surplus productions when analyzed in line with the farming system of the locality. They were only $27(12.9 \%)$ of them who owned relatively large land size. On the other hand, 18 respondents which were $8.6 \%$ of the sample respondents do not have plot of land. They either take land from the owners where they share production with the owners of land. This hinders an inspiration to work. According to the information gathered from the key informants the situation is bad in other uncovered area by the sample. This is because the area is densely populated on the one case and the existing ones are owned by few individuals.

In short, the study found that members of cooperatives, who were younger, had smaller pieces of land, which results in low earning. This study is supported by D'Haese \& Shumeta (2016) whose study confirmed that members of cooperatives, who were older, had larger pieces of land and earned more.

Figure 4.4: Land Ownership of the Sample Respondents

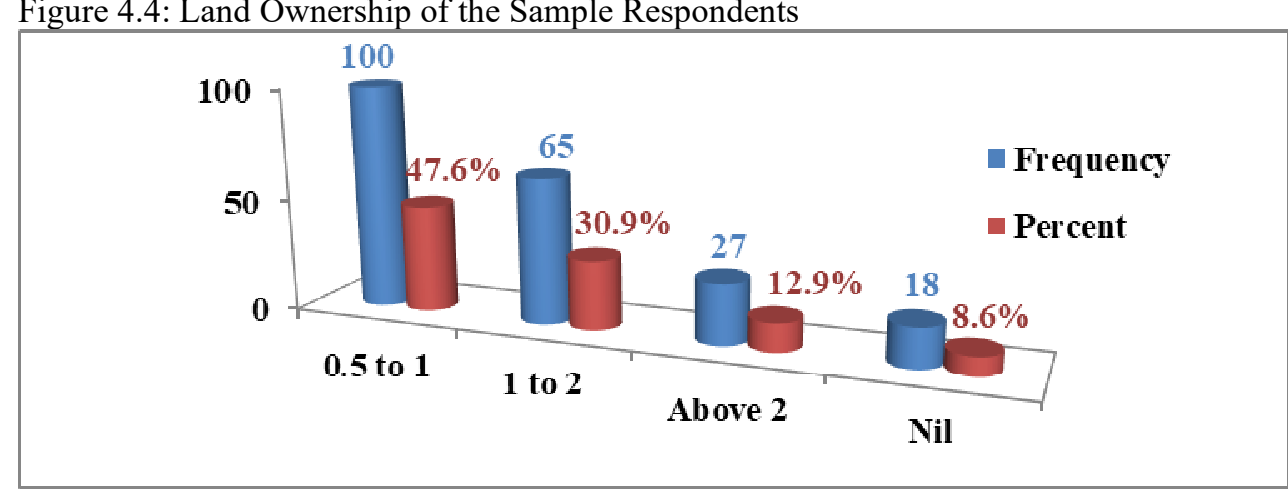

Source: Field Survey, 2019

As both large and small family sizes have their own consequence depending on the living standard of the dwellers, the family size of the sample respondents was identified. Accordingly, majority (56.7\%) of the sample respondents' family size is below 6 , about $32 \%$ of them have family size ranging from $6-9$ and $3.8 \%$ of them have family size above 12 . This shows more than averages of the respondents have family size which was supposed by CSA whereas; about $43.5 \%$ of them have above the average which can be taken as large family size. This has influence on respondents with nil and small plots of land especially on large family size where 
dependency ratio is high. Thus, as depicted by demographers, population with inactive age group can retard the economic growth since they consume the production.

Study conducted by some researchers show that there is positive relationship between household heads, educated members, more land and few family size. According to Ahmed \& Mesfin (2017), cooperative membership was found to be more beneficial for household heads with higher education, more land and fewer children

In order to simply analyze the relationship between the awareness created and the willing of membership of the respondents, duration of joining the cooperative of the respondents was the other area of attention.

Figure 4.5: Duration of Joining the MPCs by Sample Respondents

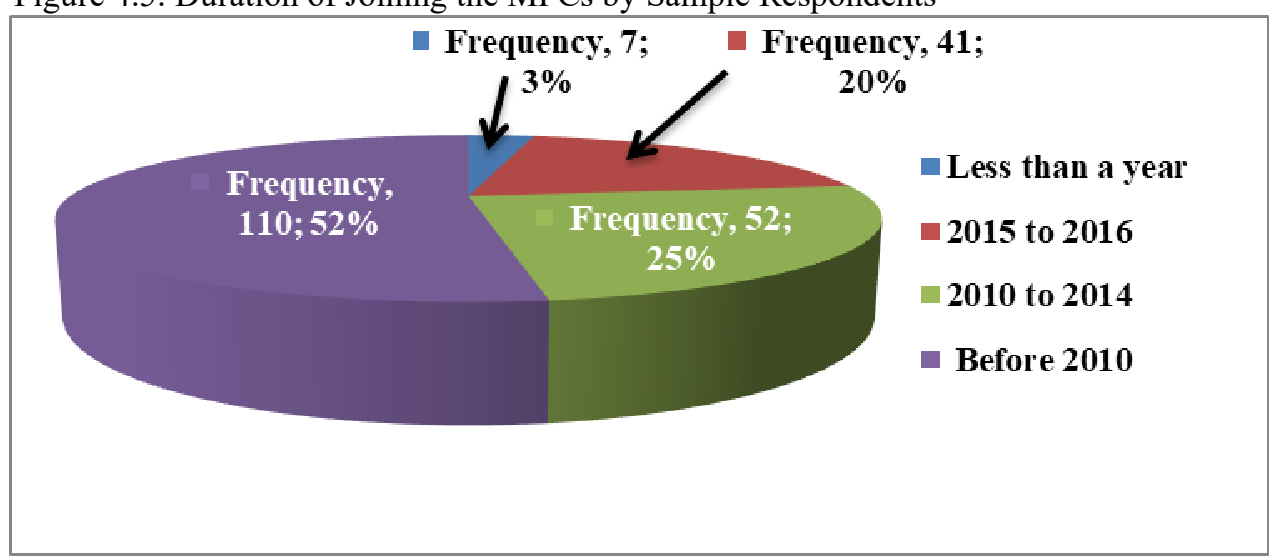

Source: Field Survey, 2019

As indicated in Fig 4.5 above, majority of the respondents (52\%) stayed in the cooperatives before 2010 and $25 \%$ of them joined the MPCs from 2010-2014. Whereas, $20 \%$ (41) of the respondents became member from 2015-2016 and 3\% of them stayed for below a year.

Thus, when observing at their proportion, it is possible to get required information from those who became members since long period of time and who recently joined. On the other hand, it also shows the level of inspiration to be membership. This fact is not only in the sample respondents, but also for the general member of the district as identified from the general document of the district cooperative office. This shows the level of joining the cooperative was decreasing from 2014 to the day of survey. This requires the district cooperative office to check their awareness creation or to look into the cooperative members itself.

\subsection{The Overall Situations of the MPCS in the Study Area}

Each multi-purpose cooperatives included in the sample has management committee who is responsible for the overall operation. The management committee comprises of members such as chair person, purchaser and accountant. These particular cooperatives are engaged in marketing of agricultural inputs such as fertilizer (DAP \& UREA), improved seeds and agro chemicals to their members. Besides, they are also engaged in the output grins marketing. The cooperatives also sell these to non-members in the community after fulfillment of the members' demand.

\subsubsection{Welfare Status of Sample Respondents}

The general welfare status which is also reflected in quality of living is assessed as per the multi-dimensional poverty index (MPI) across three dimensions; education, health and living standard. Consequently, from the sample respondents, $2.9 \%$ (6) had children aged 7 and above not attending school whose age is matured enough to enter grade one. While, $3.8 \%(8)$ of them had students dropped-out of school at the time of data collection. This needs encouraging the families to keep their children in the school for the dropout and sending to school those who are not attending.

With regard to an electricity facility in the study area, $44.8 \%$ (94) of sample respondents reported to have the service while $55.2 \%$ (116) of the respondents were deprived of the facility. Of those who reported to have the facility; $30 \%$ (66) had got from government.

The other area of welfare status measurement is access to potable clean water. As far as access to potable water is concerned, only $52.3 \%$ (110) respondents stated that they use spring water, while the rest $(48.6 \%)$ of them get treated water. According to the respondents, it seems government is the most dominant stakeholder to provide clean drinking water to the study area and provided the facility to around $32.9 \%$ (69) of the beneficiary respondents, 8.6\% (18) got the facility form NGO and the remaining 6.2\% (13) got from their cooperatives' effort. In response for the type of toilet used by the household, all the sampled respondents replied to have own built private toilet.

Regarding materials used for flooring, of the sample respondents $84 \%$ of respondents reported they used 
dirt for flooring. The remaining $16 \%$ respondents used sand. Nearly $83 \%$ of the respondents used wood as their basic cooking fuel, $9 \%$ used charcoal and $8 \%$ used dung for cooking.

In response to adaptation to technology, out of the sample respondents (50.5\%) owned radio, 29.5\% possess mobile phone, $5.7 \%$ owned Television, $1.4 \%$ of them owned refrigerator and $3.4 \%$ of the respondents reported that they have Vehicle like (2) mini-bus, taxi (3) and 1(bike). On the other hand, $6.2 \%$ (13) of them did not own any of the properties mentioned. In short, as far as the living standards of the sample respondents were concerned, most of them are at comparative better condition.

Furthermore, report from the district cooperative office indicated that members of cooperatives utilized about $88 \%$ of agricultural inputs like fertilizers, selected seeds and chemicals. In addition to this, the result of FGDs made with some participants and observation of existing situation between the members and nonmembers shown the same thing. That means with regard to technological usage habits of members was relatively high. Consequently, the comparison verified that members of the MPCs were in a better condition of understanding about the benefits of making use of agricultural inputs and also the timing they have to sell their agricultural outputs. The finding is in line with the study of Abebaw \& Haile (2013) who denoted that cooperative members were found to have better access to extension services and greater fertilizer adoption than non-members. Likewise, in the study of Abate et al. (2014) it is confirmed that higher use of technology and productive inputs is higher among members of cooperatives and they are more technically efficient than outsiders.

\subsubsection{Membership Status of Study the Study MPCs}

With regard to the respondents' relationship with their respective organizations, almost all of the sampled respondents were full membership. And they all further confirmed that there was no external pressure in joining the MPCs.

Table 4.1: Sample MPCs, Members, Year of Establishment (GC) and Capital in ETB

\begin{tabular}{cccccc}
\hline No. & Names of MPCs & & $\begin{array}{c}\text { Number of } \\
\text { members }\end{array}$ & $\begin{array}{c}\text { Year of } \\
\text { establishment (GC) }\end{array}$ & $\begin{array}{c}\text { Initial Capital } \\
\text { ( ETB) }\end{array}$ \\
\hline 1 & Lalisa Lalo & (A) & 760 & 2006 & $184,228.00$ \\
2 & Lalisa Buko & (B) & 140 & 2005 & $26,457.00$ \\
3 & Burka Dongoro (C) & 240 & 2006 & $56,400.00$ \\
4 & Feyisa Keleyi & (D) & 490 & 2004 & $22,048.00$ \\
5 & Bikiltu Atosi & (E) & 155 & 2016 & $15,948.00$ \\
\hline 6 & Total & & 1,785 & - & 305,081
\end{tabular}

Source: Compiled from Cooperative Office of the District, 2019

As indicated in Table 4.1, MPCs (A) \& (D) have more members as compared to others. As far as their initial capital is concerned, MPCs "C", "B", "D" and "E" are almost closer to each other. On the other hand, the initial capital of MPC " $\mathrm{A}$ " is relatively high as compared to the other cooperatives.

As it is explained from key informants and also confirmed by field observation, all the MPCs have better opportunity to meet the target they are formed for. But to perform more, the activities of members, the role of the management committee and professional's support plays crucial role to determine their fate. Table 4.2: MPCs' Members in the Three Consecutive Years (2016 to 2018) (in GC).

\begin{tabular}{cllccccc}
\hline No. & \multicolumn{2}{c}{ Name of MPCs } & Initial & 2016 & 2017 & 2018 & Rate of \\
\hline 1 & Lalisa Lalo & (A) & 760 & 838 & 986 & 1,002 & 19.6 \\
2 & Lalisa Buko & (B) & 140 & 493 & 580 & 605 & 22.7 \\
3 & Burka Dongoro (C) & 240 & 502 & 591 & 596 & 18.7 \\
4 & Feyisa Keleyi & (D) & 490 & 702 & 824 & 835 & 18.9 \\
5 & Bikiltu Atosi & (E) & 155 & 155 & 159 & 162 & 4.5 \\
\hline 6 & Total Average & 1,785 & 2,690 & 3,140 & 3,200 & $79.3 / 19$ \\
\hline
\end{tabular}

Source: Compiled from Document, 2019

As indicated in Table 4.2, the data in the cooperatives office shows that in MPC (A), members increased by the rate of $19.7 \%$ in 2018 than 2016. When we compare these five MPCs, members in each MPC were aggregating. The average rate of growth of members is $19 \%$ as calculated from the year 2016 and $79.3 \%$ from the year of establishment. Specifically, the rate of growth in MPC (B), (A), (D), (C) \& (E) was 22.7\%, $19.6 \%, 18.9 \%, 18.7 \%$ and $4.5 \%$ respectively. The members in the entire sample were increasing at high rate exception with the case of (E) which was growing slowly. In short, the rate of increment in the case of MPCs (A), (C) \& (D) was almost uniform, but the case of MPC (B) is higher of all.

People join cooperatives because of various reasons. As the principles indicate membership to cooperative is open and voluntary; it is not obligatory to become a member of certain cooperative. It implies that it is open to all who are able to use their services and willing to accept certain tasks of membership, without gender, social, racial, political or religious discrimination (ICA, 1995). 
In connection to this, the study result portrays that the rationale of being members in MPCs is to obtain multifaceted services such as: To get periodic dividend, employment, loan, input, output, consumer goods and training. In this regard, respondents indicated multiple reactions based on the degree of importance. Accordingly, to get access to agricultural input was valued as either highly important or critically important by $82.8 \%$ of respondents. Likewise, $68.3 \%$ reported to get access to loan as either highly important or critically important and to get access to dividend was also replied by $65.7 \%$ of respondents as either highly important or critically important. In the same manner, $57.4 \%$ and $56.6 \%$ of respondents has shown their interest either highly or critically important as to get access to consumer goods and employment respectively. This implies these five areas are the priority interest that motivated respondents to become members.

On the contrary, $18.8 \%$ and $44.5 \%$ of respondents verified their interest to join were to get access to training and output market respectively. To get access to training and output market was also shown by $41 \%$ and $39.2 \%$ of respondents as either not important or slightly important respectively. This indicates the significance of training and selling their produce through MPC is not well known by the members.

Moreover, about $29.1 \%$ and $18.9 \%$ of respondents' motivation is termed as either not important or slightly important to get access to employment and loan respectively. This also implies the significant role to be played by MPCs is undermined by members at their entrance, this further shows members' lack of awareness.

Table 4.3: Criteria for Getting Membership of the MPCs

\begin{tabular}{lccccc}
\hline \multicolumn{1}{c}{ Criteria } & $\begin{array}{c}\text { Not } \\
\text { Important }\end{array}$ & $\begin{array}{c}\text { Slightly } \\
\text { important }\end{array}$ & $\begin{array}{c}\text { Moderately } \\
\text { important }\end{array}$ & $\begin{array}{c}\text { Highly } \\
\text { Important }\end{array}$ & $\begin{array}{c}\text { Critically } \\
\text { Important }\end{array}$ \\
\hline Ability to contribute the initial capital & $11 \%$ & $12.4 \%$ & $24.9 \%$ & $49.3 \%$ & $2.4 \%$ \\
Ability to pay the periodic payment & $2.4 \%$ & $11 \%$ & $26.8 \%$ & $46.9 \%$ & $12.9 \%$ \\
Promise to buy the MPCs product/services & - & $6.8 \%$ & $46.9 \%$ & $49.3 \%$ & - \\
\hline Promise to sell outputs to/through MPCs & $1.4 \%$ & $10.5 \%$ & $10.6 \%$ & $39.2 \%$ & $38.3 \%$ \\
\hline
\end{tabular}

Source: Field Survey, 2019

As depicted in Table 4.3, the majority of the respondents $(49.3 \%)$ reported the promise to buy the MPCs product/services as highly important for getting MPCs membership followed by $46.9 \%$ conforming to moderately important and the remaining $6.8 \%$ corresponding to slightly important.

Almost equally, ability to pay periodic payment was considered as criteria for getting membership by $46.9 \%$ of respondents as highly important, and followed by $26.8 \%$ said it is moderately important criteria. Whereas, $12.9 \%$ replied as it is critically important and $11 \%$ and $2.4 \%$ of them agreed as it is slightly important and not important respectively.

Promise to sell the MPC product/service got 39.2\% vote to be highly important criteria followed by $38.3 \%$ vote to be critically important while ability to contribute the initial capital got vote of $10.5 \%$ and $10.6 \%$ to be slightly important and moderately important criteria for being member in MPCs respectively. Lastly, $1.4 \%$ of them responded that it is not important.

\subsubsection{Types of Services Provided by MPCS in the Study Area}

Cooperatives play an increasingly important role in economic growth, poverty reduction and democratization in low and middle income countries. Lack of vital service or low levels of competition provides a business opening for cooperatives and creates opportunities to gain valuable economic and social benefits. To be effective, cooperatives need: sound business practices; strong membership participation; support of an efficient apex organization facilitating economic and legal environment.

Of the MPCS, it is clear that the primary role is serving their members. But they have a variety of multiple roles in economic, social and governance area. At present cooperatives in Ethiopia play vital role in input supply service, Value addition and financial service (FCA, 2010).

With regard to the types of services of the MPCs in the study area, there are multiplicities of services that members got from their respective cooperatives though the extent varies.

As revealed by $93.3 \%$ of the respondents, the type of service they get is marketing of agricultural input supplies such as fertilizers, improved seeds and chemicals from their respective cooperatives which is rated as highly important. Whereas, 3.8\% of them reacted as slight important and $6(2.9 \%)$ did not respond.

On the other hand, $47.1 \%$ of the respondents argued that the provision of loan and credited as highly important, while $21.9 \%$ and $30.9 \%$ i.e., $52 \%$ of the respondents supposed this case as either not important or slightly important in this regard. This implies the recital of the MPCs in credit and loan service is low, which contradicts with the hope of respondents at the time of joining the MPCs.

Likewise, marketing agricultural product, marketing consumer goods and training services replied as highly important, by $46.2 \%, 41.9 \%$ and $43.8 \%$ respectively. In the same way, responses from $58.1 \%, 56.2 \%$ and $53.8 \%$ confirmed that marketing consumer goods, training and marketing agricultural products are either not important or slightly important respectively. This signifies the provisions of these services are also low in the study area.

The types of services termed under others are services creating both horizontal and vertical linkage of the 
cooperatives, saving and infrastructure supplies (like road, school, clinic and etc.). In these areas, the reaction of the respondents termed as either not important or slightly important as $34.3 \%$ and $39.5 \%$ respectively, which is together about $73.8 \%$. This shows less attention is given to such services, which indicates the area of attention to be paid by concerned bodies.

Discussion made through FGDs and key informants also show that other than serving the members, they provide various services for the surrounding communities. In general, almost all the agricultural inputs were distributed by the MPCs and creating employment opportunity, which is by large self-employment are the first and second ranking services in the study area.

In short, when we consider their motivation to become member is to get manifold services from the MPCs. However, currently they are not in a position to provide multifaceted services rather they are focused only on some selected services where marketing agricultural inputs is large proportionate.

\subsection{Contribution of MPCs in the Economic Development in the Study Area}

Several literatures in the field of cooperatives development ascertained that cooperatives can play indispensable role in promoting the local communities' capital accumulation and asset building which in turn are key for the overall socio-economic development.

\subsubsection{Resource Mobilization and Capital Formation by the Sample Cooperatives}

In local economic advancement, resource mobilization and capital formation are play significant role for local economic development (Adugna, 2013). Theoretically, cooperatives can achieve this by saving and investing themselves as economic entity, and by supporting the saving and asset acquisition efforts of local people (especially the members) through different mechanism such as improving their access to various services (like saving and credit, input and output market), and creating employment/livelihood diversification opportunities among others. And, such resource mobilization and investment process could promote efficient utilization of local resources, attract more resources from elsewhere to the locality; and thereby trigger local economic development.

To confirm this argument, their response indicated that almost all sample MPCs contributed to local people's asset building and capital accumulation, which in turn could help to promote local employment and income generation opportunities and thereby contribute for development livelihood of the local communities and the growth of the locality. As data collected shows, all MPCs have undergone marvelous change in their capital balance. For instance, MPC " $\mathrm{C}$, had about 3.5 million, while MPC "B" have nearly 2.4 million accumulated capital balance. Likewise, MPC "A" had nearly 1.8 and MPC "D" had about 1.4 million capitals balance. Whereas, MPC “E”, accrued 244,908 ETB which seems lesser as compared to others' capital. To sum up, their capital increased from 305,081 to 9.3 million ETB.

Apart from analyzing the collective income of the MPCs, FGDs conducted with some participants indicated that the income status of the members of the MPCs is relatively better of those nonmembers. This view is supported with the study of Bernard et al. (2008); Anullo \& Getnet (2012) who came up with the findings cooperative farm incomes in Ethiopia to be higher compared to those outsiders.

The sources from where the samples MPCs earn the noted capital are the other issues assessed. Accordingly, their response shown that it was from the varieties of activities they are engaged in. Among these, distribution of agricultural input has great share while marketing agricultural products like coffee, fruits and vegetables, honey and animal husbandry (sheep, chicken, etc.) fattening of oxen are also the other source in all the MPCs. All the MPCs also get capital from the supply of consumer goods like sugar and oil. On the other hand, dividend obtained from the share of cooperative bank and purchase of coffee seedling play significant role in case of MPCs "C and B". Investment expenditure in long term maturing assets such as houses, agricultural tools and household equipment are also the other sources.

Table 4.4: Capital of the Sample MPCs (in ETB)

\begin{tabular}{lllccc}
\hline No & $\begin{array}{c}\text { Names of Multi-purpose } \\
\text { Cooperatives }\end{array}$ & Initial Capital & $\begin{array}{c}\text { Capital balance at the end } \\
\text { of 2018 (GC) }\end{array}$ & Change in capital \\
\hline 1 & Lalisa Lalo & (A) & $184,228.00$ & $1,966,114.00$ & $1,781,886.00$ \\
2 & Lalisa Buko & (B) & $26,457.00$ & $2,389,959.00$ & $2,365,502.00$ \\
3 & Burka Dongoro (C) & $56,400.00$ & $3,579,599.00$ & $3,523,199.00$ \\
4 & Feyisa Keleyi & (D) & $22,048.00$ & $1,414,435.00$ & $1,392,387.00$ \\
5 & Bikiltu Atosi & (E) & $15,948.00$ & $260,856.00$ & $244,908.00$ \\
\hline 6 & Total & & 305,081 & $9,610,963$ & $9,307,882$ \\
\hline
\end{tabular}

Source: Compiled from the District Cooperative Office, 2019

\subsubsection{Profit Status of the Sample MPCs}

In order to ensure their survival and also to meet the target they established for, cooperatives should be profitable. In connection to this, to evaluate their profitability, their capital during the three consecutive periods during 2016, 2017 and 2018 G.C. were taken into consideration. Accordingly, the profit status of MPC "C" is the highest 
followed by MPCs "D”, “A”, "B” and "E” respectively.

On the other hand, when we compare the amount of profit earned with the number of members in each MPC, "C" ranks first whose dividend is 778.36 ETB when shared to its members. This is followed by MPC "E", whose share is about 556.25 ETB, MPC " $\mathrm{E}$ " is $445.64 \mathrm{ETB}$, that of "B" is about $375.95 \mathrm{ETB}$ and "B" is 296.55 ETB (Table. 4.4). From these, it can be deduced that the status of all the MPCs is promising and supposed suggestions applied, they will be by far this.

Table 4.5: Profit Status of Sample MPCs (in ETB)

\begin{tabular}{|c|c|c|c|c|c|c|}
\hline \multirow[t]{2}{*}{ No. } & \multirow[t]{2}{*}{ Name of MPCs } & \multirow{2}{*}{$\begin{array}{l}\text { Initial } \\
\text { Capital }\end{array}$} & \multicolumn{3}{|c|}{ Capital status during three consecutive years (GC) } & \multirow{2}{*}{$\begin{array}{c}\text { Profit } \\
2018 \\
\end{array}$} \\
\hline & & & 2016 & 2017 & 2018 & \\
\hline 1 & Lalisa Lalo & $184,228.00$ & $549,390.3$ & $964,448.00$ & $1,966,114.00$ & $297,144.5$ \\
\hline 2 & Lalisa Buko (B) & $26,457.00$ & 402,543 & $1,650,682.7$ & $2,389,959.00$ & $227,448.3$ \\
\hline 3 & Burka Dongoro (C) & $56,400.00$ & $350,954.56$ & $1,905,504.1$ & $3,579,599.00$ & 463,902 \\
\hline 4 & Feyisa Keleyi $\quad$ (D) & $22,048.00$ & $370,481.4$ & $912,308.25$ & $1,414,435.00$ & $372,111.2$ \\
\hline 5 & Bikiltu Atosi & $15,948.00$ & $15,948.00$ & $181,007.00$ & $260,856.00$ & $90,112.7$ \\
\hline 6 & Total & 305,081 & $1,689,317.26$ & $5,613,950.05$ & $9,610,963$ & $1,450,718.7$ \\
\hline
\end{tabular}

Source: Compiled from the District Cooperative Office, 2019

In addition to assessing secondary sources, further investigation was made. Consequently, FGDs and interviews of the key informants acknowledged the following. Members have the right to share the dividend they get; but they were adding to their capital rather than receiving it in cash. As they mentioned, if they use all opportunities their capital might go up. Even though this is the case, it is also worth mentioning that respondents stated that their enterprises are not performing well as expected especially when looking at existing potentials of the study area. So, this calls for the sustenance of professionals constantly.

\subsubsection{Investment Trends among the Sample MPCs}

As obviously known resource mobilization would have far reaching effect on local economic development and communities' livelihood improvement if it is efficiently reinvested in productive areas/assets. The Keynesian macroeconomic model stated that consumption and investment are largely dependent on the economic movement whereas economic growth will result in increasing income and thus expanding consumption and investment (Desalegn, 2019). This is a cyclical relationship in economics. This shows the types of expenditures made determine the cycle of the economic growth. In line with this, data from Table 4.5 indicates the majority of the samples MPCs are generating money and hence becoming profitable. However, when we look at the nature of their expenditure area, this motivates additional assessment.

Concerning the area where they invest their income, most of the sample respondents provided multiple answers. Accordingly, $89 \%$ of the sample respondents reported that their expenditure goes to investment on construction of warehouse while $82.9 \%$ of them confirmed that their expenditure was to school construction as contribution. As the study area is one of the coffee producing areas, $77.1 \%$ of them were investing on coffee processing machine, $76.2 \%$ are willing to invest on coffee plantation, $73.8 \%$ of them were investing on buying of shares and $63.8 \%$ of them are interested to invest animal rearing. From this, we can conclude that the great amount of investment went to the construction of warehouse. The main reason for large investment to go to construction of warehouse is due to the fact that the major service provided by the sample MPCs is marketing agricultural input.

On the other hand, $43.8 \%$ are investing on buying grain meal, $41.9 \%$ are purchasing office equipment, and investment on retail shops account for $26.7 \%$. Contribution for health center construction, Contribution for access Roads Construction and Investment on Construction of Office 20.5\%, 23.3\% and 22.9\% respectively are significant in the study area. There are also other investment areas though their figures are not as such high as others.

As far as Keynes theory is concerned, investment is the most important economic factor for a nation. It is the main source of employment creation and the main factor of economic growth. Investment induces the economic prosperity and welfare improvement in general. Even if this is the case, as it is understood from the response of the sample respondents, leaders and field observations most of the sample cooperatives have not made significant investment as compared with the existing potentials.

As it is realized from the responses of key informants, FGDs, and personal observations, the investment capacity of the study cooperatives is undermined by multitudes of problems such as limited capital base; lack of qualified manpower, lack of innovative approaches, lack of diversified activities, lack of committed and experienced leaders; limited awareness and commitment of members are some of the problems identified. In addition to this, lack of adequate government support, credit facilities and other necessary technical supports are also the other problems on government side to be tackled. Lack of adequate stakeholders' support is also among the problems that have limited their investment capacity. 


\subsubsection{Employment Creation and Livelihood Diversification by Sample MPCs}

As it is stated in the report of ILO (2001), cooperatives continue to play an important role in employment promotion and poverty alleviation both as production enterprises mainly of self-employed and as provider of service to members. Accordingly, an estimated 280 million jobs are provided by cooperatives to salaried employment, which is $20 \%$ more than multinational corporations. This is in fact a conservative figure considering that cooperatives provide not only direct employment, but also self-employment, indirect and induced employment in both urban and rural areas around the world and thus provide income teeth members and employees in the form of shares at surplus wage and salaries or profits depending on the type of cooperative (FCA, 2011).

Thus, to assess its reality in the study area, under this section, the performance of sample MPCs in employment creation and livelihood diversification is assessed in light of this argument.

\subsubsection{Direct Employment Creation}

According to Jurgon (ILO COOP) (1994), cooperatives in Africa have created a sizeable number of salaried jobs; yet, their biggest employment creation potential lies in the field of direct and indirect self-employment. As to the same report, cooperatives are the second largest employer in many African countries and some countries around the world, being surpassed only by the government. However, the role being played by the study MPCs seems far less than adequate when seen in light of such empirical evidences. As it is indicated in table 4.13 above, data gathered from the sample respondent shows that only $7.1 \%$ have got direct employment opportunity from their MPCs. Similarly, only a total of 157 direct employments (i.e. 123 males and 34 females) have been created by the sample MPCs that are contractual employment in type.

As it is proved from the respondents, all MPCs have created direct employment opportunity for both members and non-members though the figure varies in each MPC. Of the employment opportunity created, there is a great disparity in gender where about $78 \%$ are male and about $22 \%$ are females. As information obtained from the key informant shows the type job opportunity created in the study area is the main reason for an extensive gap created between the two sexes.

Likewise, the employment opportunity with the origin of the employee was identified. Accordingly, $98.7 \%$ of them are local people and only $1.3 \%$ opportunity was for people coming from other area. In connection to the economic status of the employed people, information obtained from the key informants show $91.7 \%$ (144) are people from the low income groups and $8.3 \%$ (13) of them are from the middle income groups. In addition, most of the job opportunities created by these MPCs are low salary earning that can be discussed in the coming topic.

With regard to the area of direct employment opportunity created, the evidence obtained shows; the major job opportunity is guard where $38.2 \%$ of both sexes are employed (36.9\% for male and only $1.2 \%$ of females). This is followed by warehouse related works where $22.3 \%$ are employed and dominated by males. On the other hand, $14.6 \%$ direct employment opportunity is identifying best coffee seeds for getting high quality product. This employment area is with no males. From this, we can conclude that more than $75 \%$ of the direct employment opportunity is from three work areas: guard, warehouse and identifying/screening best coffee seeds. These works are labor intensive by their nature as compared with others and additionally do not require sophisticated skills.

Unlikely, jobs those require skills like grain meal operating $6.4 \%$, accounting and audit $5.2 \%$, driving $3.8 \%$ and purchasing $3.8 \%$ all together created job opportunity for $19.2 \%$. Thus, in order to create better employment opportunity in the study area, attention has to be given on diversifying the activities of MPCs.

As pointed out by committee for the promotion and advancement of cooperatives (COPAC) (2000); Somavia (2002), cooperatives are specifically seen as significant tools for the creation of decent jobs and for the mobilization of resources for income generation. In line to this, even if there is a creation of job opportunity, the salary the majorities get is low. The data compiled confirms that about $88.5 \%$ of the workers are getting a monthly wage, which is less or equal to 1000 ETB per month, whereas only $11.5 \%$ of them are earning an amount surpassing 1000 ETB per month. When we compare the two sexes, proportionate to their number about 68 males are getting a monthly salary of equal or less to $900 \mathrm{ETB}$, about 10 females are earning equal or less to 900 ETB per month. This shows, though more opportunity is obtained by males in terms of wage, it is low. The reason identified for the relatively better earning for females is the advantage they get from collecting better coffee seeds as large number of them engaged in it.

In general, though the direct employment opportunity created by the study MPCs can be taken as a good start, it is, however, very low by any standard. As information obtained from the sample respondents reveals and verified by observation, with an amount of wage they earn it is difficult to survive. As a result, almost all of them are engaged in other supplementary activities rather than relying on the opportunity created for them by MPCs. So, this can be one of the problems in taking their attention to others rather than focusing on the area. Furthermore, as realized from the leaders' response and field observation, hosts of problems are identified so that attention should be given to the aforementioned problems to make MPCs as efficient and effective as possible. 


\subsubsection{Self-Employment and Income Diversification Roles of Sample MPCs}

Report from ILO shows that over 130 million non-agricultural workers in the world are self-employed, and the numbers are increasing rapidly in areas where unemployment is high and alternatives are limited. This Selfemployment normally includes employers (including the working owners' of unincorporated businesses), ownaccount workers, and members of workers' cooperatives and other employee-owned enterprises. The selfemployed create employment for themselves as well as for family members, regular and casual employees and apprentices.

In line with this argument, job opportunities created to the sample MPCs members as a result of selfemployment are numerous resulting from multiple response provided. In view of that, about 13 main job areas where respondent employed indirectly are identified. Of these, respondents above average are engaged in production of (grain, fruits and vegetables) and coffee planting, which account for $96.2 \%$ and $65.2 \%$ respectively. Animal rearing and animal fattening are replied by $44.3 \%$ and $34.3 \%$ members respectively. Poultry and modern and transitional bee keeping are responded by $26.7 \%$ and $24.3 \%$ samples respectively.

Likewise, $18.1 \%$ of respondents are engaged in marketing different consumer goods. The response of the key informants shows that, in about $12(63.2 \%)$ of the cases, cooperative members are engaged in selfemployment activities such as animal rearing. Similarly, in about $12(63.2 \%)$ of the case, the members are undertaking in traditional small scale poultry activities. And, in $32(15.2 \%)$ of the cases, the cooperative members undertake other activities such as (barber, preparation and sale of local drinks (food) and butchers). Besides, in $22(10.5 \%)$ the members undertake activities like marketing agricultural produce such as grains, fruits, vegetables and coffee, while in $6(2.9 \%)$ of the cases, the members are engaged in driving vehicles (2mini-bus, 3 taxis and 1 bike).

Furthermore, as information obtained from the key informants/leaders, and personal observations reveals two farmers are linked with Japan investors to sell their bee products (honey) and they are earning about 200,000 to 500,000 ETB each per year. They also further described that since the area's climatic condition is favorable to produce coffee and other agricultural products (grain, fruit and vegetables) majorities of respondents are engaged in these areas. Coffee production in the study area is relatively at better status, if it is wisely managed and other stakeholders participate by far high employment opportunity would be created.

Generally, information obtained from key informants and personal observations further indicate that the MPCs should be managed properly by the management committee in accordance with the objectives stated. Members should also actively participate in their own fate to improve their condition, linkage should also be created in order that members get good market for their production, credit facilities and capacity building program should also be given beyond what is going on.

According to the ILO report, cooperatives do have a comparative job creation advantage over other types of enterprises: they are labor intensive by nature, they are cost-effective because of member commitment and participation, they generate economies of scale and scope through horizontal and vertical integration, they establish links between the informal and the formal sectors, and they put economic and social development on a broader base.

Thus, employment creation is one of the most crucial issues in developing countries like Ethiopia, where unemployment rate is very high. They do this by promoting local investment, by cultivating endogenous micro and small enterprises, and by attracting other business from elsewhere to the locality. The growth of such local enterprises is very essential in enhancing the forward and backward linkage between different sectors and actors, and also in better utilizing the local human and material resources for the sustainable development of a locality. This indicates they have multifaceted benefits such as improving the income and livelihood of local community, generate more revenue for government (through income tax), and thereby promote local economic development.

In summary, the surveyed MPCs could play vital role in mobilizing resources for local economic development, if they are democratically organized and managed. The study also revealed that, though it is not adequate, the sample MPCs mobilized some local resources such as human and financial resources by promoting the participation of local people in development, and by pulling their meager resources together for better use.

Besides, they also have attracted resources from elsewhere outside the locality in the form of loan, donation and other means. If used productively, such resources would have far reaching multiplier effect on local economic development. It could encourage local business development both inside and outside agriculture, and thereby promote the diversification of economic activities at local level and generate more employment opportunities. Furthermore, it can promote investment in social infrastructure such as roads, health centers, schools, and other socio-economic institutions, that are basic in attracting more resources either locally and/or from elsewhere for local development.

In this regard, the performance of the study MPCs can be considered as a good start, but far from being adequate. As noted by key informants and FGDs, some local communities (the members) are now enabled to acquire different assets of their own like residential house, and other livestock such as cattle and sheep; while 
some of them have also engaged in activities such as production of grain, fruits and vegetables, and in micro and small scale business activities. Hence, enhancing and sustaining such roles is essential to unleash the enormous potential in this regards.

\subsection{Major Problems of the Study MPCS}

Since 1994, the government of Ethiopia has made efforts to promote a new generation of cooperatives that differ from their predecessors that were put in place under previous regime. Despite success stories of some or few cooperatives, there were also critical problems in cooperatives sectors.

To assess the tangible problems, most of the sample respondents provided multiple answers. Consequently, in the study area, among several challenges faced, the major ones were lack of professional and motivated managers. The samples MPCs in the study area don't have professional managers due to three reasons: The viability of the cooperative is not always ensured due to low organization technical supports and follows up by the concerned bodies. Besides, the low level of educational and entrepreneurship skill, and poor salary and incentives were also mentioned under the case others.

Lack of long term credit and loan hinder the investment of MPCS in different projects that would have economic benefit to members. This is indicated by $89.5 \%$ of the samples. Furthermore, interview with the key informant of experts of cooperative office and cooperatives management body shows there is high loan demand but unwilling to refund on time, which diminishes their financial capacity.

At the same time, the members' economic and financial power to strengthen their MPCs is very week, which shows lack of enough capital. This is also confirmed from the suggestions of $89 \%$ of the respondents. This verifies, these two problems are the main hitches as realized the large proportion of the sample respondents.

The other challenges were the members' participation in various matters to control and solve the problems emerging. As to Spear (2004), the principle of democratic member control, however, requires active member participation in the decision-making and administration of a jointly owned cooperative. It is based on the principle of one vote per one member, which was the approach used in the cooperatives studied. However, in practice, the members were reported to be very passive in exercising this right. For example, the data revealed difficulties in organizing management, as the members are reluctant to take part in joint affairs and activities. This problem exists in the entire sample MPCs, but the degree is high in the case of Lalisa Lalo \& Feyisa Keleyi MPCs.

Moreover, cooperatives require members' commitment to finance and use the business and select knowledgeable directors who hire a competent manager. Concerning this, as it is revealed from $45.7 \%$ of the sample respondents, participation of members is low. For instance, member's participation in making investment in their association was not as expected. The low attendance in annual meeting also supports this conclusion. This was due to various reasons i.e., insufficiency of dividend incentives, low direct employment opportunities created by MPCs and others are some of the causes listed out.

Research conducted by ILO shows cooperatives have to have up-to-date information exchange mechanisms on the price of products, the volume of production, the type of activities and government policies, so as to adjust their activities and services in line with supply and demand. However, the cooperatives in Ethiopia are poorly networked both locally and internationally. In the same way, in the study area, lack of updated information specially for marketing their output was a serious problem as revealed by $67.6 \%$ of the sample respondents. As they further described, this fact is the result of lack of enough information. Due to this, they were forced to sell the product at low price in local area. One of the key measures of cooperative health is growth of total assets, the physical and financial building blocks of the business. In this aspect the study confirmed that there were low performances in asset growth because of innovative managers, which was addressed by $71.9 \%$.

With regard to diversifying activities, there were good opportunities because the government has good policy to enhance cooperatives development. Regardless of this, the sample MPCS couldn't utilize the opportunities. They were made only little effort to diversify the activities i.e., only on the activities like supply of consumers' goods, invest on retail shops and etc.

In the study area, the result indicated that government provided some technical assistance to the MPCs. But the finding indicated that government support was not enough for the development of the MPCs as approved by $79.5 \%$. There is also a case when expertise lack knowledge and skill as identified from the key informants. Moreover, they proved that there is also unstable structure which would result in high staff turnover. Thus, the study found that there is an inadequate governmental institutions support. Whereas, absence of efficient and skilled management and limited financial capacity are the other problems confirmed by $65.7 \%$ and $89 \%$ of the sample MPCs respectively. Similarly, $75.7 \%$ respondents identified that poor infrastructure facilitates are the major challenges faced in almost all the MPCs. The infrastructure problem (road, transportation, energy, agricultural processing, bank and etc.) in the area hinders provision of inputs, consumer goods and marketing). Generally, well-structured infrastructural facilities such as better road, electricity and communication particularly 
internet access, etc. contribute greatly for MPCs' growth. Thus, from these, we can suggest that to attain the intended objectives, there should be support concerned organizations that provide over service, it needs sound business practice, strong membership participation and improving infrastructural facilities to facilitate economic and conducive environment.

Figure 4.6: Major Problems of the Study MPCs

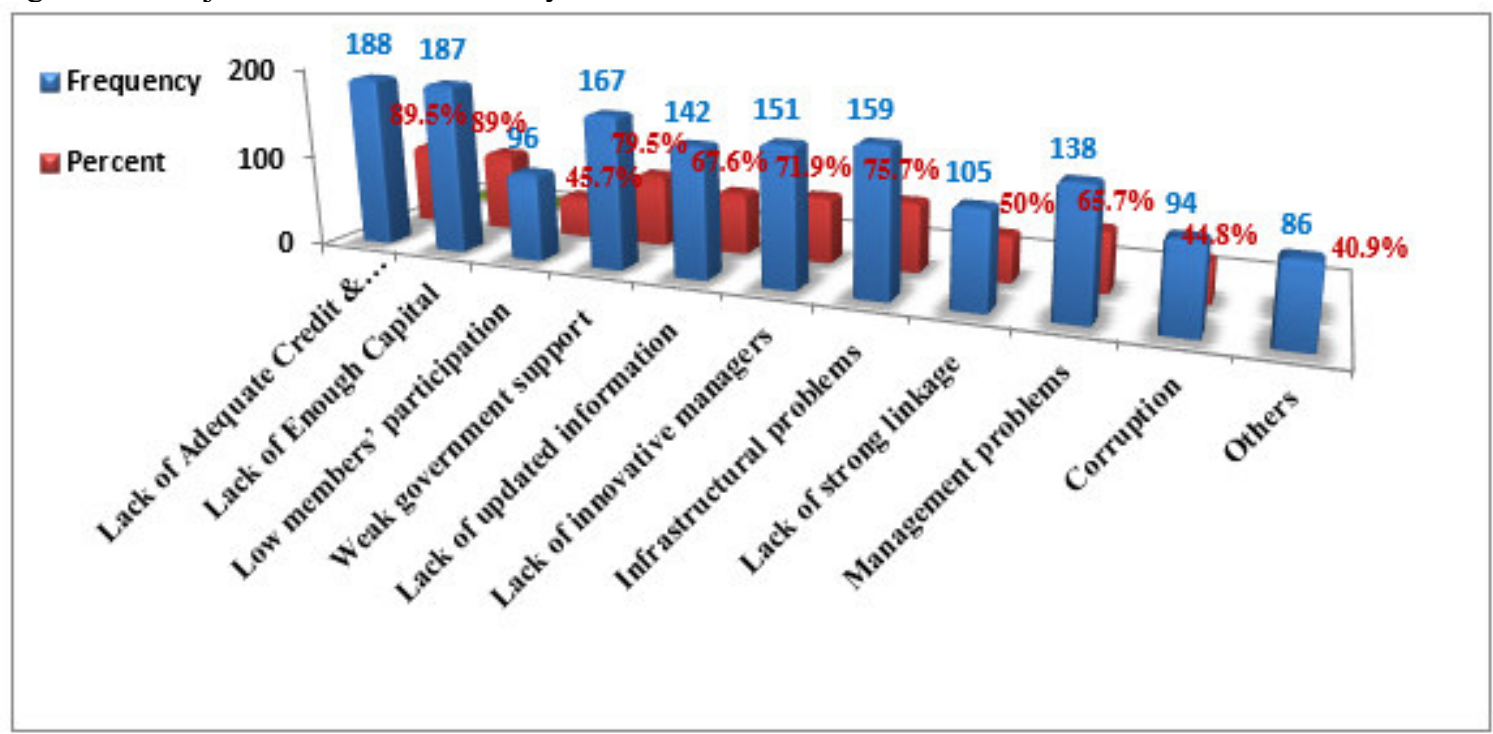

Source: Field Survey, 2019

In summary, key informants in the same way confirmed the presence of the mentioned problems. Accordingly, in the study area major structural, operational and managerial problems include: Low member's loyalty (low members' participation) due to inadequately addressing their needs and problems by their organization, lack of capital, lack of innovative managers, weak government support (legal, audit, inspection), absence of reliable and up to date market info and networking problem with partners, poor infrastructural facilities in the area, and etc.

Corruption is also the other problem as responded by $44.8 \%$ of the samples. In practical, the leaders and the members themselves are not in a position to struggle and combat in the study area. In most cases, this condition retards the development of MPCs.

Other than government organizations, all stakeholders should participate to solve the problem of financial and human resource capacity among MPCs. Of these, the role NGOs play is very notable. They can facilitate the establishment of primary cooperatives and cooperative unions by working with the district cooperative office and cooperatives management committees. They can provide a wide range of supports to cooperatives, including material support, advocacy on fair trade, cooperative restructuring and/or establishing new cooperatives, technical support, training and other capacity building supports. Though this is the case, in the study area, there is only World Vision Organization, whose coverage and magnitude of support is limited. Thus, lack of NGOs is the other problem identified from discussion made with members and experts.

As to ILO (2001), cooperatives like private and other organizations should develop viable horizontal networks and vertical linkages with partners, in order to deliver quality services to their members and increase their sustainability within a free and competitive market. In connection to this, viable reality shows that there is weak horizontal and vertical relation, which means weak linkage between individual members vs. primary cooperatives; primary cooperatives with cooperative unions; and Unions with federation.

Moreover, lack and shortage of warehouse, transport, weak public relation activities, weak documentation, and less women participation as membership and leadership were also critical challenges. These are categorized under the case others as realized by $40.9 \%$ of the sample respondents. Thus, to enhance and sustain the role of MPCs in the study area, priority based attention should be given to the aforementioned problems.

\section{Conclusion and Proposed Interventions \\ 5.1 Conclusion}

As far as the contribution of MPCs in the study area is concerned, the study showed that they played some roles in community development. It helped in improving the standard of living of their members. Basically cooperative has been evolved to meet up the fundamental needs of the rural people by their accumulated savings. As data collected shows (Table 4.5), all MPCs have undergone astonishing change in their capital balance and 
also their profit status is promising though it is not as expected. The study also revealed that the sample MPCs mobilized some local resources such as human and financial by promoting the participation of local people in development, and by pulling their meager resources together for better use. The performance of the study MPCs can be taken as a good start, it is, however, very low by any standard. This ratifies, the role being played by the study MPCs seems far less than adequate when seen in light of realistic indications.

Some of the major problems identified in hindering its achievement are lack of professionals and motivated managers, lack of devoted management committees, limited capital base; low members' participation, insufficient dividend, lack of innovative approaches and lack of diversified activities, limited awareness, lack of up-to-date information and commitment of members, lack of adequate government support, credit facilities and other necessary technical supports etc. are in the study area (Figure 4.6).

\subsection{Proposed Interventions}

To enhance the role of MPCs in the economic development in the study area; cooperatives members, concerned government bodies, non-governmental organizations and other stakeholders have to strive to improve their role in the study area:

- MPCs have to be supported in their resource mobilization and investment efforts by easing access to financial services, land, information, and other basic resource; and provide necessary technical and professional supports like audit and advisory services.

$\Rightarrow$ Building the capacity of primary cooperative management committees and their staff so that they get management committees that own modern cooperative management skill. In addition to this, they should hire professional staffs depending on their financial capacity.

$\Rightarrow$ The district office and the union should search market for its affiliated member cooperatives and in integrating with other business enterprises to play their expected role in this regard.

- Advocacy works should be done to strengthen the awareness of members, leaders and non-members to enable all understand the significance of cooperatives using different Medias and experience sharing opportunities. Equal participation of males and females should be promoted.

$\Rightarrow$ Measures to improve access to finance for disadvantaged groups should be adopted and some informal economy should be formalized largely by government.

- MPCs better to diversify the provision of services expected of them so as to increase their income. They should also improve their financial position by selling additional shares to existing members, by attracting new members and engaging in profitable business activities. This improves current asset position of the cooperatives instead of basing their operating capital on external sources.

- Establishing strong linkage between cooperatives i.e., horizontal and vertical collaborations between themselves; and also scale up and sustain their linkage with other development actors to increase their business scale and operational efficiency along with improved market access. Higher cooperative organs specially, cooperative federation and Oromia cooperative agency should play their role to strengthen these linkages.

$\Rightarrow$ To improve cooperatives involvement in the rural development programs, infrastructural problems existing in the area (road, electricity and telecom etc.) should be improved.

- The saving culture of the members should be improved so as to be able to diversify their activities and be transformed to other economic activities by accumulating capital.

\section{Acknowledgments}

This study has been accomplished because of the direct and indirect support and encouragement of many individuals. First and foremost, I would like to thank the Almighty God for this wonderful opportunity he has given me to write this research paper. Next, I would like to extend my sincere thanks and gratitude to my beloved wife sr. Lelise Firisa Duguma for her usual encouragement and practical assistance in every activity I was performing to overcome the struggle of life. With great pleasure and deep sense of indebtedness, I express my gratitude to my beloved sons Kotim Desalegn, Succoth Desalegn and Tolif Desalegn for their tolerance and encouragement to enable me finish this paper without worrying about their interest. I am thankful to the West Wollega Zone cooperative office specifically Mr. Ababe Tsegaye senior expert of the office for his commitment to provide me necessary information. My gratitude also goes to Lalo-Assabi cooperative office experts and members of the MPCS for their cooperation in providing me important data and for allowing me to observe their activities, filling the questionnaires and their willing to take part in all the invitation made for them to collect all data to accomplish this study.

\section{References}

Abate, G., T., Francesconi, G., N., \& Getnet, K. (2014). Impact of Agricultural Cooperatives on Small holders' Technical Efficiency: Empirical Evidence from Ethiopia. Annals of Public and Cooperative Economics, 
$85(2), 257-286$.

Https://Onlinelibrary.Wiley.Com/Doi/Abs/10.1111/Apce.12035

Abebaw, D. \& Haile, M., G. (2013). The Impact of Cooperatives on Agricultural Technology Adoption: Empirical Evidence from Ethiopia. Food Policy, 38, 82-91. https://www.sciencedirect.com/science/article/abs/pii/S0306919212001030

Adugna, H. (2013). Co-operative Approach to Community Livelihood Improvement: The Case of Ada'a District, Oromia Regional State, Ethiopia, Published: International Journal of Development and Sustainability, Vol. 2, No. 3, pp. 2124-2145, Ethiopia.

Ahmad, D., B. (2005). The Role of Cooperative Societies in Economic Development: Published in the Official Journal of the Department of Public Administration, Ahmadu Bello University, Zaria-Nigeria.

Ahmed, M., H. \& Mesfin, H., M. (2017). The impact of Agricultural Cooperatives Membership on the Wellbeing of Smallholder Farmers: Empirical Evidence from Eastern Ethiopia, Agricultural and Food Economics, 5(1), 6.

https://agrifoodecon.springeropen.com/articles/10.1186/s40100-017-0075-z

Alemu Tereda (2011). The Role of Agricultural Marketing Cooperatives in Reducing Rural Poverty: The Case of Yirgachefe and Sidama-Elto Cooperative Unions in SNNP Regional State.

Anullo, T. \& Getnet, K. (2012). Agricultural Cooperatives and Rural Livelihoods: Evidence from Ethiopia: Annals of Public and Cooperative Economics, 83(2), 181-198. https://onlinelibrary.wiley.com/doi/abs/10.1111/j.1467-8292.2012.00460-x

Baarda, James, R. (2006). "Current Issues in Cooperative Finance and Governance; Background and Discussion Paper". Cooperative Programs, Rural Development: Department of Agriculture, USA, pp.11-17.

Banaszak, I. (2008). Determinants of Successful Cooperation in Agricultural Markets: Evidence from Producer Groups in Poland. Strategy and Governance of Networks, Heidelberg: Physical-verlag.

Bernard, T., Taffesse, A., S., \& Gabre-Madhin, E. (2008). Impact of Cooperatives on Smallholders' Commercialization Behavior: Evidence from Ethiopia. Agricultural Economics, 39(2), 147-161. https://onlinelibrary.wiley.com/doi/abs/10.1111/j.1574-0862.2008.00324.x

Bezabih Emana (2009). Cooperative: A Path to Economic and Social Empowerment in Ethiopia. Coop ${ }^{\text {AFRICA }}$ Working Paper, No.9, ILO, Dare Salam, $\mathrm{pp}^{9-14}$.

Bolton, L. (2019). Economic Impact of Farming Cooperatives in East Africa: Knowledge, Evidence and Learning for Development (K4D) Helpdesk Report 535. Brighton, UK: Institute of Development Studies.

Chukwu, S., K. (1990). Economics of the Cooperative Business Enterprise. Marburg, Germany.

COPAC (2000). The Contribution of Co-operatives to Employment Promotion, Grand Saconnex, Geneva, Switzerland.

Creswell, John. W. (2006). Qualitative, Quantitative and Mixed Methods Approach, Second Edition, Saga Publication.

Desalegn Fekadu (2013). Factors Affecting the Delivery of Quality Educational Services and Facilities in Ethiopia, the Case of Gimbi Town Primary Schools (Oromia Regional State, West Wollega Zone): Lap Lambert Academic Publishing, ISBN: 978-3-659-40910-3.

Desalegn Fekadu (2019). Assessment of the Role of Research in Molding Cooperative Policies: Public Policy and Administration Research, Vol.9, No.5, DOI: 10.7176/PPAR.

Desalegn Rahmato (1994). "After the Derge: An Assessment of Rural Land Tenure issues in Ethiopia." Institute of Development Research, No 147, AAU, Ethiopia.

D'Haese, M. \& Shumeta, Z. (2018). Do Coffee Cooperatives Benefit Farmers? An Exploration of Heterogeneous Impact of Coffee Cooperative Membership in South-West Ethiopia: International Food and Agribusiness Management Review, 19(4), 37-52.

FAO (2005). Access to Rural Land and Land Administration after Violent Conflict: Land Tenure Studies, ISBN: 92-5-105343-x, Rome.

ICA (1995). Statement on the Cooperative Identity, in Review of International Cooperation, Vol. 88, No 3.

ILO (2001). "The Role of Cooperatives and Other Self-Help Organizations in Crisis Resolution and

Socio-Economic Recovery." ILO Cooperative Branch, Geneva.

Islam, S., Mazariegos, V., Nagarajan, G., \& Zaman, L. (2015). Effects of Farmer Cooperatives on Expanding Agricultural Markets in Developing Countries: A Systematic Review. Social Impact, USDA.

https://apps.fas.usda.gov/fais/public/files/Food\%20for\%20Progress\%20Learning\%20Agenda\%20

Jemal Mahmud (2008). Analysis of the Role of Cooperatives in Agricultural Input out Put Marketing in Eastern Zone, Tigray Region: MA Thesis, Mekelle University, Ethiopia.

Jürgen Schwettmann (ILO COOP) (1994). Cooperatives and Employment in Africa: Final Report of the Regional Advisor on Cooperatives for Eastern, Southern and Central Africa (October 1988 to March 1994), ILO Cooperative Branch: Occasional Discussion Paper 97-1, Geneva.

Kifle Tesfamariam (2015). Cooperative Movement in Ethiopia: Development, Challenges and Proposed 
Intervention: Journal of Economics and Sustainable Development, Vol.6, No.5, ISSN 2222-1700.

Nuredin Mohammed, Byeong Wan Lee (2015). Role of Cooperatives in Rural Development, the case of South Nations Nationalities and People Region, Ethiopia: Science Journal of Business and Management, Vol.3, No.4, 2015, pp.102-108.

Ruhul Amin \& Mohammed Mahin Uddin (2014). Socio-Economic Impacts of Cooperative Societies: An Empirical Study: Socrates, Vol. 2, No.7, PP. 179.

Somavia, J. (2002). Farmer and Consumer Cooperatives Structure and Classification: The Farmers' Cooperative Yardstick, Cooperative Extension Service, University of Kentucky, USA. ILO Recommendations No.193 on Cooperatives.

Spear, R. (2004). 'Governance in democratic member-based organizations', Annals of Public and Cooperative Economics, 75 (10), 33-59.

Yamane, Taro (1967). Determining Sample Size, Florida Cooperative Extension Service,University of Florida.

Zeuli, K. \& Cropp, R., (2004). Cooperatives: Principles and practices in the $21^{\text {st }}$ century, Madison: University of Wisconsin, USA, pp.1-23. 